\title{
Meta-analysis of the effects of laidlomycin propionate, fed alone or in combination with chlortetracycline, compared with monensin sodium, fed alone or in combination with tylosin, on growth performance, health, and carcass outcomes in finishing steers in North America ${ }^{1}$
}

\author{
N. Cernicchiaro, $*$ M. Corbin, $\uparrow$ M. Quinn, $\$$ F. Prouty,,$\S^{2}$ M. Branine,\# and D. G. Renter*3 \\ *Center for Outcomes Research and Education, College of Veterinary \\ Medicine, Kansas State University, Manhattan 66506; †Zoetis, Harrison, NE, 69346; \\ FFeedlot Health Management Services, Amarillo, TX 79119; §1530 Sun City Blvd Suite 120, PMB 467, \\ Georgetown, TX 78633; and \#Zinpro Corporation, Research and Nutritional Services, Canon City, CO 81212
}

\begin{abstract}
The objective of this research was to use data from multiple studies to comprehensively quantify the effects of feeding 1) laidlomycin propionate (LP), alone and/or in combination with chlortetracycline, compared with 2) monensin sodium (MS), alone and/or in combination with tylosin, at commercially approved dosages, on ADG, DMI, feed efficiency (FE), mortality, and carcass characteristics (HCW and liver abscesses). A secondary objective was to explore potential sources of heterogeneity among the comparative effectiveness studies. A systematic review of peer-reviewed literature and industry reports was used to identify studies that included direct comparisons of these treatments in finishing steers in North America. Random-effects meta-analysis models of performance, carcass, and health-related outcomes were fitted with extracted data, consisting of a total of 17 data sets comprising a total of 135 pens and 13,603 steers. Results showed that pens of steers fed LP had increased ADG (live and carcass adjusted), DMI, and HCW compared with those fed monensin $(P<0.05)$. However, liver abscesses were
\end{abstract}

more common in LP-fed cattle than in MS-fed cattle $(P<0.05)$, presumably because of differences in the concurrently fed antimicrobials. No significant effects $(P>0.05)$ were identified for FE or for health-related outcomes (overall and cause-specific mortality). There was a substantial amount of heterogeneity in outcomes among studies, and when pen size and type of production setting were included in mixed-effects metaregression models, they accounted for only a small proportion of the between-study heterogeneity found in the meta-analysis models. Therefore, caution should be exercised when interpreting summary estimates in the presence of substantial heterogeneity. However, these results provide comprehensive information on the comparative effects of different ionophores across multiple studies and multiple years, states, and production settings. These unique results can enable quantitative and informed decisions by potential end users of these feed additives that are widely used in the U.S. beef industry for reducing the costs of beef production through enhanced cattle performance.

Key words: feedlot performance, finishing steers, ionophore, laidlomycin propionate, meta-analysis, monensin sodium

(C) 2016 American Society of Animal Science. All rights reserved.

J. Anim. Sci. 2016.94:1662-1676 doi:10.2527/jas2015-0086

\section{INTRODUCTION}

\footnotetext{
${ }^{1}$ Funding for this project was provided by Zoetis, LLC, and the College of Veterinary Medicine, Kansas State University. Several of the authors (MC, MQ, FP, and MB) currently or previously worked for the pharmaceutical companies that distributed the products evaluated in this study.

${ }^{2}$ Retired.

${ }^{3}$ Corresponding author: drenter@vet.ksu.edu

Received November 10, 2015.

Accepted January 13, 2016.
}

Over $90 \%$ percent of all U.S. feedlots over 1,000 cattle capacity include an ionophore as part of their nutritional management program (USDA, 2011). Ionophores fed to feedlot cattle promote the efficient use of feedstuffs through improved rumen fermentation efficiency by altering the end products available for absorption and metabolism and, therefore, can reduce the cost of beef production by improving animal 
growth and feed efficiency (Russel and Strobel, 1989; Birkelo, 2003; Callaway et al., 2003; USDA, 2011). The efficacy of ionophores for improving cattle performance outcomes has been well documented in numerous studies (reviewed in Vogel, 1995; Birkelo, 2003). In fact, the efficacy of monensin in beef cattle was recently evaluated using an extensive meta-analysis of data from 40 peer-reviewed articles and 24 trial reports (Duffield et al., 2012). However, similar analyses of data from comparative effectiveness studies - those that directly compare the effectiveness of using different ionophore products in a feedlot setting - have not been previously reported.

There has been an increased emphasis on the use of meta-analysis in the animal science and veterinary literature as an important tool to synthesize treatment effects across multiple studies, particularly when biologically or economically important effects may be difficult to detect without large sample sizes (Donner et al., 2001; Duffield et al., 2012). Complementary techniques such as meta-regression (O'Connor et al., 2014b) can be used to identify factors associated with heterogeneity of responses across studies, and systematic reviews and bias assessments can be used to assure that a repeatable approach is used for inclusion of studies (Duffield et al., 2012; O'Connor et al., 2014a). The primary objective of this systematic review and meta-analyses was to determine the effects of feeding laidlomycin propionate (LP), alone and/or in combination with chlortetracycline, compared with feeding monensin sodium (MS), alone and/or in combination with tylosin, at commercially approved dosages, on feed efficiency (FE), ADG, DMI, mortality, liver abscesses, and HCW of finishing steers in North America.

\section{MATERIALS AND METHODS}

\section{Systematic Review of the Literature}

The original research question was formulated as: What are the effects of LP (Cattlyst; Zoetis LLC, Florham Park, NJ), fed alone and/or in combination with chlortetracycline (Aureomycin; Zoetis LLC), compared with MS (Rumensin; Elanco Animal Health, Indianapolis, IN), fed alone and/or in combination with tylosin (Tylan; Elanco Animal Health), at commercially approved dosages, on performance (ADG, FE, and DMI), health (cause-specific and overall mortality), and carcass characteristics (HCW and liver abscesses) of finishing steers in North America in studies that have a randomized control trial design?

The research question comprised 4 main components: 1) population (finishing steers), 2) interventions (LP and MS alone or in combination with chlortetracycline and tylosin, respectively), 3) outcomes (ADG, DMI,
FE, HCW, mortality, and liver abscesses), and 4) study design (randomized controlled trial [RCT] designs). To generate a complete list of all primary research that could answer our research question, search terms were created to account for these components. The actual search terms and Boolean expressions used or the format varied depending on the search engine. Some of the search terms that were used included "(ruminant OR cattle OR cow OR feedlot OR fed beef OR beef OR steer) AND (ionophore OR cattlyst OR laidlomycin OR aureomycin OR chlortetracycline OR tylosin OR tylan OR monensin OR rumensin) AND (performance OR growth OR average daily gain OR adg OR daily gain OR weight gain OR hot carcass weight OR hcw OR carcass weight OR mortality OR deaths OR liver abscess OR hepatic abscess OR feed gain OR dry matter intake OR dmi) AND (trial OR clinical trial OR ret OR randomization OR rcbd)." Electronic databases accessed through the Kansas State University library included Medline/ Pubmed (http://www.ncbi.nlm.nih.gov/pubmed; accessed March 1, 2015), Agricola (http://agricola.nal.usda. gov/; accessed March 1, 2015), CAB Direct (http://www. cabdirect.org/; accessed March 1, 2015), Scopus (includes Medline and Embase; http://www.scopus.com/; accessed March 1, 2015), Google Scholar (https://scholar. google.com/; accessed March 1, 2015), and USDA-ARS Current Research Information System (CRIS; http:// cris.nifa.usda.gov/cgi-bin/starfinder/0? path $=$ crisassist. txt\&id $=$ anon\&pass $=\& \mathrm{OK}=\mathrm{OK}$; accessed March 1, 2015) and TekTran (http://www.ars.usda.gov/services/ tektran.htm; accessed March 1, 2015). In addition, articles retrieved from a hand search of published documents as well as industry reports were reviewed for inclusion. Reference lists from review articles were reviewed to identify relevant articles not captured during the search of electronic databases. Final reports and data from RCT comparing LP to MS at commercial approved doses, which were initiated by industry researchers and pharmaceutical companies and performed in feedlots in multiple states, were identified and reviewed for relevance.

\section{Relevance Screening}

The title and abstract of articles identified through electronic databases and a hand search, as well as unpublished industry reports, were screened for relevance based on preset inclusion and exclusion criteria (Table 1). Articles deemed relevant to direct comparisons of interventions are depicted in Table 2. Two reviewers independently assessed the relevance of the articles and reports. When conflicts arose, those were resolved by consensus. Only results from studies reporting direct comparisons between LP and MS at commercially approved dosages (LP [Cattlyst] at approximately $11 \mathrm{~g} / \mathrm{t}$ 
Table 1. Exclusion and inclusion criteria for eligibility of studies assessing the effects of laidlomycin propionate versus monensin sodium on different performance, health, and carcass outcomes in finishing steers

\begin{tabular}{|c|c|c|}
\hline Item & Inclusion criteria & Exclusion criteria \\
\hline Cattle type & Beef cattle & Dairy, cow-calf, other \\
\hline Sex/category & Steer & Heifer, mixed \\
\hline Breed & Continental, British, or crossbreed & Holstein \\
\hline Age & Finishing cattle & Calves, background cattle, pasture \\
\hline Days on feed & $80-240 \mathrm{~d}$ & $<80$ or $>240 \mathrm{~d}$ \\
\hline $\begin{array}{l}\text { Interventions and } \\
\text { dosage }\end{array}$ & $\begin{array}{l}\text { Direct comparisons between laidlomycin propionate (approximately } 11 \mathrm{~g} / \mathrm{t} \mathrm{DM} \text { ) } \\
\text { and monensin sodium (approximately } 27 \text { to } 33 \mathrm{~g} / \mathrm{t} \mathrm{DM} \text { ) with or without antimi- } \\
\text { crobial combinations (chlortetracycline [ } 350 \mathrm{mg} / \text { animal per day] and tylosin [9 } \\
\mathrm{g} / \mathrm{t} \mathrm{DM}] \text {, respectively) }\end{array}$ & $\begin{array}{l}\text { Indirect comparisons and doses other than those } \\
\text { commercially approved }\end{array}$ \\
\hline Administration route & In feed & Any other than in feed delivery \\
\hline Performance outcomes & Mean and SE (SD, variance, or $P$-value) of ADG, DMI, and feed efficiency & No measures of variability provided \\
\hline Carcass outcomes & $\begin{array}{l}\text { Mean and SE (SD, variance, or } P \text {-value) of } \mathrm{HCW} \text {, number or proportion of total } \\
\text { livers with abscesses, total livers with no abscesses, A abscesses, and } \mathrm{A}+\text { ab- } \\
\text { scesses }\end{array}$ & No measures of variability provided for $\mathrm{HCW}$ \\
\hline Health outcomes & $\begin{array}{l}\text { Number or proportion of respiratory deaths or mortality, digestive m.ortality, } \\
\text { overall mortality, total mortality, and removals }\end{array}$ & \\
\hline Study design & Randomized controlled trials & Laboratory (in vitro) and observational \\
\hline Region/country & North America (the United States, Canada, and Mexico) & Other than the United States, Canada, and Mexico \\
\hline Language & English & Other than English \\
\hline Publication year & $1994-2015^{1}$ & See below ${ }^{1}$ \\
\hline
\end{tabular}

${ }^{1}$ Initially, the search was restricted to studies published after 1994; however, we expanded the search to also include articles published before 1994.

DM with or without chlortetracycline [Aureomycin = $350 \mathrm{mg} /$ animal per day; Zoetis LLC; the level indicated for control of bacterial pneumonia] and MS [Rumensin] at $27-33 \mathrm{~g} / \mathrm{t}$ DM with or without tylosin [Tylan $=9 \mathrm{~g} / \mathrm{t}$ DM; Elanco Animal Health]) in the United States and produced from their corresponding manufacturers were included in the analysis. If citations did not pass the screening, those studies were not further considered. Originally, the search strategy for year of publication was set to start at 1994, the year when LP was released to the market; however, that criterion was relaxed to allow retrieval of studies from any publication year. Although not yet approved by the U.S. Food and Drug Administration at the time, 3 industry reports from 1989 (Freeman et al.; Hale; and Lofgreen, unpublished data) and 1 peer-reviewed article from 1992 (Galyean et al., 1992) were obtained and retained for further analysis as they comprised direct comparisons between LP and MS at commercial dosages (Table 3; Freeman et al., 1991; Galyean et al., 1992). Full-text articles or full reports from studies that passed the relevance screening were obtained and their risk of bias was assessed and then they were advanced to the data extraction step.

\section{Risk of Bias Assessment}

After full-text article retrieval, 2 reviewers independently evaluated the risk of bias using a set of quality criteria designed to assess internal and external validity factors. Disagreements were resolved by consensus.
Quality criteria evaluated issues related to confounding, selection, and information bias as well as external validity issues. Internal validity (or bias) factors assessed included study design (RCT), study implementation (randomization and blinding), and study analysis (clustering and outcome assessment). External validity (or generalizability) factors appraised included animal production setting (commercial or research feedlot) and study population (finishing steers). Risk of bias was assessed for each design feature in each study as present, absent, or not reported. This evaluation was conducted to determine the potential influence of bias on results but not as an exclusion criterion. Hence, no articles were removed based on the risk of bias assessment. A further assessment of the risk of bias consisted of stratified meta-analyses and meta-regression analyses conducted to explore pen size and type of production setting as potential sources of between-study heterogeneity.

\section{Data Extraction}

A data extraction spreadsheet was developed, where each column represented a field of interest for extracting data from the industry reports and full papers. Data extraction was independently performed by 2 reviewers and disagreements were resolved by consensus. Data extracted included the following: author; title; year of study; month of study; study location (country, state, and city); sex; days on feed; pen size; number of pens per treatment; number of animals per treatment; 
Table 2. Number of articles retrieved from electronic databases, hand search, and industry reports and number of relevant articles identified for direct comparisons of interventions

\begin{tabular}{lrcc}
\hline \hline & $\begin{array}{c}\text { Original } \\
\text { search }^{2}\end{array}$ & $\begin{array}{c}\text { Relevance } \\
\text { screening }\end{array}$ & $\begin{array}{c}\text { Relevant } \\
\text { articles }^{4}\end{array}$ \\
\cline { 2 - 4 } Source $^{1}$ & \multicolumn{3}{c}{ No. of studies } \\
\hline Electronic databases (J) & 1,447 & 67 & $3^{5}$ \\
$\quad$ Scopus & 212 & 17 & 0 \\
Pubmed & 158 & 27 & 0 \\
Agricola & 360 & 12 & 0 \\
Google Scholar & 52 & 0 & 0 \\
TekTran & 59 & 0 & 0 \\
$\quad$ USDA Current Research & 4 & 1 & 0 \\
Information System (CRIS) & & 4 & 2 \\
$\quad$ CAB Direct & 4 & 17 & $9^{6}$ \\
Hand search (CP) & 34 & 145 & $14^{7}$ \\
Industry reports (IR) & 2,330 & & \\
Total & & & \\
\hline
\end{tabular}

${ }^{1} \mathrm{~J}=$ peer-reviewed journal publications; $\mathrm{CP}=$ conference proceedings (reports available online); IR = industry reports. Agricola (http://agricola. nal.usda.gov/; accessed March 1, 2015), CAB Direct (http://www.cabdirect. org/; accessed March 1, 2015), Google Scholar (https://scholar.google.com/; accessed March 1, 2015), Medline/Pubmed (http://www.ncbi.nlm.nih.gov/ pubmed; accessed March 1, 2015), Scopus (includes Medline and Embase; http://www.scopus.com/; accessed March 1, 2015), TekTran (http://www. ars.usda.gov/services/tektran.htm; accessed March 1, 2015), and USDAARS Current Research Information System (CRIS; http://cris.nifa.usda. gov/cgi-bin/starfinder $/ 0$ ? path $=$ crisassist.txt\&id $=$ anon $\&$ pass $=\& O K=O K ;$ accessed March 1, 2015).

${ }^{2}$ Includes duplicates (articles retrieved in more than 1 database).

${ }^{3}$ Relevance screening based on screening of title and abstract and after removal of duplicates, non-English articles, and studies from regions other than North America, among other criteria.

${ }^{4}$ Only direct comparison of treatments.

${ }^{5}$ Three articles comprising 4 data sets.

${ }^{6} \mathrm{Nine}$ industry reports comprising 11 data sets.

${ }^{7}$ Total of 14 studies comprising 17 data sets in total.

breed; treatment; treatment dose; use of antimicrobials and dosage; use of implants; day of implant; other preventative measures (coccidiostatics, vaccines, and $\beta$-agonists); mean, SEM, or SD of ADG; initial weight; final weight; DMI; FE; HCW; number of morbid animals and deaths (digestive, respiratory, and any cause); and liver abscess (number, percent, total, $\mathrm{A}+, \mathrm{A}$, and no abscesses; Table 4). The FE outcome variable used consisted of the ratio of feed weight to $\mathrm{BW}$ gain, rather than the inverse (G:F), because several older study reports did not include the latter (or data for calculations). Data for each treatment group (LP and MS) pertaining to the number of pens per treatment, number of animals per treatment, mean outcomes, and their measures of variability were extracted from relevant studies. If an article reported results for different trials, given a different dietary combination or management program, or performed in a different group of animals, those results were treated as separate data sets within a study. If data from a study were reported in both an industry report and a peer-reviewed publication, the latter was used. The specific studies from which data were extracted from and that contributed estimates for different outcome-specific meta-analyses are included in Table 3.

\section{Outcome and Summary Measures}

Outcome measures pertaining to performance characteristics (ADG, DMI, FE, and $\mathrm{HCW}$ ) were computed on a live weight and/or carcass-adjusted basis, after excluding the cattle that died or did not finish. Health outcomes were extracted as proportions or percentages, or percentage of the events of interest were calculated from the studies by considering the number of events of interest reported in each treatment group as the numerator and the number of animals in each treatment group as the denominator. Definitions and units for all outcome measures are depicted in Table 3.

For performance outcomes measured on a continuous scale (Table 4), the mean of each treatment group was recorded, along with the SEM, SD, variance, or $P$-value. In all cases, those means accounted for the hierarchical structure of the study design (animals clustered within pens). Means and measures of variability for the outcomes of interest were entered into an electronic spreadsheet. Mean and SEM reported using the English system (lb) were transformed to the International System of Units system $(\mathrm{kg})$ by multiplying those values by 0.453592 . When an overall SEM was reported for each treatment group, a pooled SD was derived from the formula $\mathrm{SD}_{\mathrm{p}}=\mathrm{SEM}_{\mathrm{p}} \times\left(n_{\mathrm{p}}\right)^{1 / 2}$, in which $\mathrm{SD}_{\mathrm{p}}$ is the pooled SD, SEM $\mathrm{p}$ is the overall SEM provided by the study, and $n_{\mathrm{p}}$ is the number of individuals in both treatment groups (Lean et al., 2009). For studies reporting only $P$-values, an estimate of a common SD was computed using the mean treatment difference $\left(x_{2}-x_{1}\right)$, the $t$-statistic $\left(t_{\alpha \mathrm{dfE}}\right.$ which corresponds to the percentile from the reference distribution [tinv is the two-tailed inverse of the Student's t-distribution which can be calculated using ( $P$-value, $\mathrm{df}$ ); $\mathrm{df}=(n \mathrm{LP}+n$ MS) -2)]), and the sample size of each treatment group (n) using the following formula reported in Mederos et al. (2012): $\mathrm{S}_{\mathrm{p}}=(x 2-x 1) /\left\{t_{\alpha \mathrm{dfE}}[(1 / n 2)+(1 / n 1)]^{1 / 2}\right\}$.

For dichotomous measures (Table 4; mortality and liver abscesses), outcomes were converted to the logarithm of the odds ratios (OR) using the following formula: $\operatorname{lnOR}=\ln (a d / b c)$. The SE of the $\log$ OR were calculated as follows: $\mathrm{SE}(\operatorname{lnOR})=[(1 / a)+(1 / b)+(1 / c)+$ $(1 / d)]^{1 / 2}$, in which $a$ is the number of events in group 1 (LP), $b$ is the number of events of interest in group 2 (MS), $c$ is the number of subjects with no events in group 1 , and $d$ corresponds to the number of subjects with no events in group 2 (Bradburn et al., 1998). Data entries 
Table 3. Summary of relevant data sets that were included in meta-analysis models

\begin{tabular}{|c|c|c|c|c|c|c|c|}
\hline $\begin{array}{l}\text { First author/investigator, } \\
\text { study year }{ }^{1}\end{array}$ & Location & Source $^{1}$ & $\begin{array}{l}\text { Production } \\
\text { setting }\end{array}$ & $\begin{array}{c}\text { Number } \\
\text { of data sets }\end{array}$ & $\begin{array}{c}\text { Pens/ } \\
\text { treatment }\end{array}$ & $\begin{array}{l}\text { Steers/ } \\
\text { pen }\end{array}$ & $\begin{array}{c}\text { Steers/ } \\
\text { treatment }\end{array}$ \\
\hline Bryant T., 2010 & Oklahoma & IR & Commercial & 1 & 15 & 135 & 2,025 \\
\hline Swingle S., 2010a² & Texas & IR & Commercial & 1 & 6 & 81 to 132 & 589 to 614 \\
\hline Swingle S., $2010 \mathrm{~b}^{3}$ & Texas & IR & Commercial & 1 & 6 & 81 to 132 & 573 to 593 \\
\hline Swingle S., 1998 & Texas & IR & Commercial & 1 & 10 & 80 to 107 & 942 \\
\hline Hunsaker B., $2008^{4}$ & Colorado & IR & Research & 1 & 16 & 10 & 160 \\
\hline Hunsaker B., $2008^{5}$ & Colorado & IR & Research & 1 & 6 & 100 & 600 \\
\hline Cooper R., 2010 & Nebraska & IR & Commercial & 1 & 6 & 73 & 438 \\
\hline Hunsaker B., 2010 & Colorado & IR & Research & 1 & 6 & 10 & 60 \\
\hline Johnson E., 2009-2010 & Idaho & IR & Commercial & 1 & 8 & 100 & 800 \\
\hline Freeman A., 1989 & Kansas & $\mathrm{CP}$ & Research & 1 & 4 & 10 & 40 \\
\hline Lofgreen G., 1989 & New Mexico & IR & Research & 1 & 4 & 15 & 60 \\
\hline Hale R., 1989 & Colorado & IR & Research & 1 & 5 & 8 & 39 \\
\hline Domby E., 2010-2011 & Colorado & $\mathrm{J}$ & Research & 1 & 24 & 9 & 216 \\
\hline Gibb D., $2008^{6}$ & Alberta, Canada & $\mathrm{J}$ & Research & 1 & 4 & 15 & 60 \\
\hline Gibb D., $2008^{7}$ & Alberta, Canada & $\mathrm{J}$ & Research & 1 & 4 & 15 & 60 \\
\hline Galyean M., 1992 & New Mexico & $\mathrm{J}$ & Research & 1 & 6 & 12 & 72 \\
\hline Kreikemeier K., 1995 & Kansas & $\mathrm{CP}$ & Research & 1 & 5 & 9 & 45 \\
\hline Total & & & & 17 & 135 & & 6,779 to 6,824 \\
\hline
\end{tabular}

${ }^{1} \mathrm{~J}=$ peer-reviewed journal publications; $\mathrm{CP}=$ conference proceedings (reports available online); $\mathrm{IR}=$ industry reports; Freeman A., 1989 (Freeman et al., 1991 ); Domby E., 2010-2011 (Domby et al., 2013); Gibb D., 2008 (Gibb et al., 2008); Galyean M., 1992 (Galyean et al., 1992); Kreikemeier K., 1995 (Kreikemeier, 1997).

${ }^{2}$ No beta agonist.

${ }^{3}$ Zilpaterol hydrochloride.

${ }^{4}$ Progesterone and estradiol benzoate.

${ }^{5}$ Trenbolone acetate and estradiol.

${ }^{6}$ Steam-rolled corn.

${ }^{7}$ Ground corn.

equivalent to 0 in any of the cells $(a, b, c$, and $d)$ were replaced with a value of 0.005 to enable transformation.

\section{Data Analysis}

Extracted data were incorporated into meta-analyses models to compute summary estimates for the different outcomes of interest. The following models were concurrently fitted: 1) a fixed-effect meta-analysis, where each study was weighted using an inverse variance method, and 2) a random-effects meta-analysis DerSimonian and Laird (1986) model to account for the heterogeneity between studies. Mean differences (MD) and standardized mean differences (SMD) for continuous outcomes and OR for dichotomous outcomes and their $95 \%$ confidence intervals were obtained in metaanalysis models using the "metan" command in Stata 12.0 (StatCorp LP, College Station, TX).

Given that some of the continuous outcomes (e.g., ADG, DMI, FE) may not have been measured following the exact same procedure (a few articles did not report how some of the outcomes were measured or calculated) but likely were a reasonable proxy for the outcomes of interest, SMD also were used as summary statistics (O'Connor et al., 2014b). Therefore, summary effects for all continuous outcomes were expressed as both MD and SMD. Mean difference or difference in means esti- mates the amount by which LP changes the outcome on average compared with MS (Higgins and Green, 2011). Standardized mean differences reflect the treatment effect relative to the variability observed in the outcome in each study (Dohoo et al., 2009) and correspond to the number of SD difference. A guideline for interpreting SMD proposed by Cohen (1988) is as follows: 0.2 represents a small effect, 0.5 represents a moderate effect, and 0.8 represents a large effect (Cohen, 1988; Higgins and Green, 2011). For analyses of liver abscesses outcomes, only those studies explicitly reporting the use of ionophores concurrently fed with antimicrobials (chlortetracycline and tylosin) were included in meta-analysis models, as these specific antimicrobial drugs are fed in combination with the interventions of interest for the purpose of disease prevention.

Between-study heterogeneity was quantified using Cochrane's $\chi^{2}$ test of homogeneity $(Q)$ and the $I^{2}$ statistic (Higgins et al., 2003; Higgins and Thompson, 2004). Cochrane's Q statistic was used to evaluate whether the variation between studies exceeds that expected by chance and is used to compute the $I^{2}$ statistic: $I^{2}=$ $[(Q-\mathrm{df}) / Q] \times 100$ (Higgins et al., 2003). A $P$-values less than 0.10 indicates significant between-study heterogeneity. The $I^{2}$ statistic represents the percentage of variation across studies that is due to heterogeneity rather than chance $\left(I^{2} 25-50 \%\right.$ represents a low degree of 
Table 4. List of performance, health and carcass outcome measures, definitions, units, and type of outcomes for statistical analyses

\begin{tabular}{|c|c|c|c|}
\hline $\begin{array}{l}\text { Outcome measure } \\
\text { (acronym) }\end{array}$ & Description & Units & $\begin{array}{c}\text { Type } \\
\text { of outcome }^{1}\end{array}$ \\
\hline \multicolumn{4}{|l|}{ ADG } \\
\hline Live weight, deaths excluded & \multirow{2}{*}{$\begin{array}{l}\text { Mean number of kilograms gained daily based on total weight gained over total days } \\
\text { on feed; measurements based on live or carcass-adjusted weight; deaths not included }\end{array}$} & $\mathrm{kg} / \mathrm{d}$ & MD and SMD \\
\hline Carcass adjusted, deaths excluded & & $\mathrm{kg} / \mathrm{d}$ & MD and SMD \\
\hline \multicolumn{4}{|l|}{ DMI } \\
\hline Deaths excluded & Amount of feed cattle consume per day on a moisture-free basis; deaths not included & $\mathrm{kg} / \mathrm{d}$ & MD and SMD \\
\hline \multicolumn{4}{|l|}{ Feed efficiency } \\
\hline Live weight; deaths excluded & \multirow{2}{*}{$\begin{array}{l}\text { Feed conversion ratio: kilograms DMI to kilograms of weight gain; measurements } \\
\text { based on live or carcass-adjusted weight; deaths and removed cattle not included }\end{array}$} & $\mathrm{NA}^{2}$ & MD and SMD \\
\hline Carcass adjusted; deaths excluded & & NA & MD and SMD \\
\hline $\mathrm{HCW}$ & $\begin{array}{l}\text { Hot or unchilled weight of the carcass after slaughter and removal of head, hide, } \\
\text { intestinal tract, and internal organs }\end{array}$ & $\mathrm{kg}$ & MD and SMD \\
\hline Respiratory mortality & $\begin{array}{l}\text { Proportion of deaths attributed to BRD during the study period for each treatment } \\
\text { group }\end{array}$ & $\%$ & OR \\
\hline Digestive mortality & $\begin{array}{l}\text { Proportion of deaths attributed to digestive disturbances during the study period for } \\
\text { each treatment group }\end{array}$ & $\%$ & OR \\
\hline Overall mortality & $\begin{array}{l}\text { Proportion of deaths (due to any cause) among the study population (for each treat- } \\
\text { ment group) }\end{array}$ & $\%$ & OR \\
\hline Total mortality and removals & $\begin{array}{l}\text { Proportion of total deaths and removals (due to any cause) among the study popula- } \\
\text { tion (for each treatment group) }\end{array}$ & $\%$ & OR \\
\hline Total livers with abscesses & Total proportion of cattle with liver abscesses observed during harvest ${ }^{3}$ & $\%$ & OR \\
\hline Proportion of A livers & Proportion of cattle with 2 to 4 well-organized abscesses ${ }^{3}$ & $\%$ & OR \\
\hline Proportion of A+ livers & Proportion of cattle with 1 or more large or multiple small, active abscesses ${ }^{3}$ & $\%$ & OR \\
\hline Total livers with no abscesses & Proportion of livers with no abscesses $(\text { scored } 0)^{3}$ & $\%$ & OR \\
\hline
\end{tabular}

heterogeneity, $I^{2} 50-75 \%$ represents a moderate degree of heterogeneity, and $I^{2} \geq 75 \%$ represents high degree of heterogeneity; Higgins et al., 2003).

When the test of heterogeneity (Cochrane's $\chi^{2}$ ) tended to be significant $(P<0.10)$ in meta-analysis models, pooled summary estimates from random-effect models were presented. When the heterogeneity test of meta-analysis models did not tend to be significant $(P>$ 0.10 ), indicating that between-study differences are explicable by random variation, summary estimates from fixed-effect models were depicted. When heterogeneity is low, fixed- and random-effect models tend to produce very similar estimates. Size of study pen ( $<50$ steers/pen and $>50$ steers/pen) was considered an a priori confounder and potential cause of heterogeneity between studies. Hence, when substantial heterogeneity was identified $\left(I^{2}>50 \%\right)$, a stratified analysis (i.e., pooled estimates are obtained by each subgroup or strata) was conducted to explore size of study pens as a potential cause of heterogeneity. Moreover, meta-regression models were fitted to investigate size of study pens $(<50$ steers/pen and $>50$ steers/pen $)$ and type of production setting (commercial operation and research feedlot) as factors that could potentially explain the heterogeneity between studies. Mixed-effects meta-regression models with residual maximum like- lihood and the Knapp-Hartung variance modification were fitted using the "metareg" command in Stata.

\section{RESULTS}

\section{Systematic Review of the Literature}

A total of 2,292 articles were obtained from Medline/Pubmed, Agricola, CAB Direct, Scopus (includes Medline and Embase), Google Scholar, and USDA-ARS CRIS and TekTran and 2 were obtained from a hand search. After duplicate removal and relevance screening (i.e., screening of title and abstracts and removal of non-English articles and studies from regions other than North America), only 128 articles were deemed relevant. A further screening aiming to explore direct comparisons between treatments retrieved 5 articles: 3 obtained from Scopus comprising 4 data sets and 2 from a hand search. From a total of 34 industry reports (produced by different companies acquiring the products: Syntex, 1994; Roche, 1995; Alpharma, 2000; Pfizer, 2010; Zoetis, 2013) conducted from 1989 to 2010, 17 reports were deemed relevant, and 9 reports, comprising 11 data sets, described direct comparisons. Two industry reports were published in a peer-reviewed publication and a conference 
proceeding; therefore, the latter forms were used for data extraction purposes (Table 2).

\section{Relevance Screening}

An extensive number of studies obtained from electronic databases did not meet the inclusion or exclusion criteria (Table 2). Only data from RCT, with random assignment of cattle pens to treatments, were used in this study to assure an objective assessment of effects. Studies where the treatments were administered through a route other than in feed were excluded; studies where cattle were administered a ruminal fistula were excluded, as our goal was to include only animals administered the products under commercial-type conditions. In all studies, treatments were administered at the pen level (in feed). Only studies appropriately accounting for multiple organizational levels or clustering (animals nested within pens) in their analyses were included. Hence, multilevel models had to be applied to analyze these types of data. Studies published in languages other than English were excluded due to budgetary constraints for using translational services.

\section{Risk of Bias Assessment}

Full-text articles and reports were subjected to a risk of bias assessment evaluating a set of criteria pertaining to internal and external validity factors. All peerreviewed studies and industry reports that passed the relevance screening and met the eligibility criteria were RCT with a random assignment of animals into pens and treatments randomly assigned to pens. Blinding, however, was reported in only 1 study. Eleven of the total 14 relevant studies explicitly reported how the outcomes were measured (e.g., live, carcass adjusted, deaths in or out). The lack of independence of outcome measures due to the existence of a hierarchical organizational structure (e.g., animals within pens) and/or repeated measures was accounted for in the statistical analysis of all relevant studies. Five studies were conducted in commercial feedlots and 9 were conducted in research feedlots. The study population in all relevant studies comprised finishing steers.

Except for blinding, internal validity issues pertaining to study design and implementation were deemed of low risk. The study population of interest was considered a potential confounder, and its confounding effect was controlled for by using a restricted population (i.e., finishing steers) during relevance screening. External validity questions pertaining to population and outcomes assessment were deemed of low to unclear risk, as all studies were conducted in finishing steers and only a few studies did not explicitly define how the outcomes were measured. Another potential confounder considered a priori was the size of the study pens, and hence, a stratified analysis was conducted to determine its effect on the different outcomes of interest for both intervention groups (see below).

\section{Data Extraction and Meta-Analyses}

Data were extracted from a total of 14 articles comprising a total of 17 data sets: 6 data sets were extracted from 5 peer-reviewed publications and hand search reports and 11 data sets were derived from 9 industry reports (Table 3). Data were pooled from RCT conducted in various geographic areas of the United States and Alberta, Canada, comprising a total of 13,605 finishing steers. The Continental, British, or crossbreed steers were on feed, on average, from 112 to $187 \mathrm{~d}$. Interventions LP and MS were fed at dietary concentrations that ranged between 11 and $11.1 \mathrm{~g} / \mathrm{t}$ and 27.8 and $33.3 \mathrm{~g} / \mathrm{t}$ of feed, DM basis, respectively. Steers' initial weight ranged from 283 to $387 \mathrm{~kg}$, with a mean of $340 \mathrm{~kg}$ (SD 28). After excluding deaths and animals removed from the study, carcass-adjusted final weight ranged from 561 to $658 \mathrm{~kg}$, with a mean of $622 \mathrm{~kg}$ and SD of $31 \mathrm{~kg}$.

Results from meta-analyses are presented in Tables 5 and 6 , which include continuous and categorical outcomes, respectively. Figures 1 to 5 include forest plots used to demonstrate effects on performance and health outcomes. When using forest plots to present results, each horizontal line represents the results from 1 study or data set, depicted by the name of the first author and the publication or study year (see Table 3 for more information). The length of the horizontal line represents the $95 \%$ confidence interval for the parameter estimate (e.g., MD), the center of the shaded box represents the point estimate of the parameter, and the area is proportional to the assigned weight. The empty diamond at the bottom shows the confidence interval and the dotted vertical line represents the overall effect parameter based on random-effects (DerSimonian and Laird [1986] model; preferred estimation) models.

\section{Effects on Performance Parameters}

Meta-analyses results indicated that steers fed LP had a greater ADG, based on live and carcass-adjusted measurements, compared with steers fed MS (Table 5; Fig. 1). Likewise, feeding LP increased DMI in finishing steers compared with feeding MS (Table 5; Fig. 2). However, MD in FE based on live weight and carcassadjusted measurements were not significantly different for LP compared with MS (Table 5; Fig. 3). Although all performance outcomes were measured in the same unit, it was not clear whether all studies used the exact 
Table 5. Results obtained from random-effects meta-analysis models of the effects of laidlomycin propionate compared withmonensin sodium on performance outcomes

\begin{tabular}{|c|c|c|c|c|c|c|c|c|c|}
\hline \multirow[b]{2}{*}{ Outcome, ${ }^{1}$ units } & \multirow[b]{2}{*}{$\begin{array}{l}\text { Number } \\
\text { of data sets }\end{array}$} & \multirow[b]{2}{*}{$\mathrm{MD}^{2}$} & \multirow{2}{*}{$\begin{array}{c}95 \% \mathrm{CI}^{3} \\
\text { Lower, upper } \\
\text { MD }\end{array}$} & \multirow[b]{2}{*}{$\begin{array}{c}\mathrm{MD}=0 \\
P \text {-value }\end{array}$} & \multirow[b]{2}{*}{$I^{2}, 5 \%$} & \multirow[b]{2}{*}{$\mathrm{SMD}^{6}$} & \multirow{2}{*}{$\begin{array}{c}95 \% \text { CI } \\
\text { Lower, upper } \\
\text { SMD }\end{array}$} & \multirow[b]{2}{*}{$\begin{array}{l}\mathrm{SMD}=0 \\
P \text {-value }\end{array}$} & \multirow[b]{2}{*}{$I^{2,5} \%$} \\
\hline & & & & & & & & & \\
\hline$\overline{\mathrm{ADG} \text { (live), } \mathrm{kg} / \mathrm{d}}$ & 16 & 0.05 & $0.04,0.07$ & $<0.01$ & 92.2 & 0.61 & $0.40,0.81$ & $<0.01$ & 96.4 \\
\hline ADG (carcass adjusted), $\mathrm{kg} / \mathrm{d}$ & 8 & 0.06 & $0.04,0.08$ & $<0.01$ & 95.6 & 0.67 & $0.43,0.90$ & $<0.01$ & 97.2 \\
\hline DMI, $\mathrm{kg} / \mathrm{d}$ & 17 & 0.29 & $0.23,0.36$ & $<0.01$ & 93.4 & 0.68 & $0.53,0.83$ & $<0.01$ & 93.0 \\
\hline FE (live) & 16 & 0.02 & $-0.07,0.11$ & 0.65 & 99.9 & 0.20 & $-0.17,0.56$ & 0.28 & 98.7 \\
\hline FE (carcass adjusted) & 9 & -0.03 & $-0.08,0.03$ & 0.31 & 96.5 & -0.16 & $-0.41,0.10$ & 0.23 & 97.8 \\
\hline $\mathrm{HCW}, \mathrm{kg}$ & 17 & 5.36 & $3.86,6.87$ & $<0.01$ & 94.5 & 0.57 & $0.39,0.74$ & $<0.01$ & 95.3 \\
\hline
\end{tabular}

${ }^{1}$ For explanation of outcome measures, see Table $4 . \mathrm{FE}=$ feed efficiency.

${ }^{2} \mathrm{MD}=$ mean difference.

${ }^{3} \mathrm{CI}=$ confidence interval.

${ }^{4}$ Test ( $Z$-test) of the null hypothesis of no difference in means ( $\left.M D=0\right)$ or standardized mean differences $(\mathrm{SMD})$ between interventions $(\mathrm{SMD}=0)$.

${ }_{5} I^{2}=$ variation in MD or SMD attributable to heterogeneity $\left(I^{2} 25-50 \%\right.$ represents a low degree of heterogeneity, $I^{2} 50-75 \%$ represents a moderate degree of heterogeneity, and $I_{2} \geq 75 \%$ represents high degree of heterogeneity; Higgins et al., 2003); $P$-values for Cochran's $Q$ test $(\chi 2$ test; $\mathrm{df}=k-1$, in which $k=$ number of studies) to assess the statistical significance of between-study heterogeneity were $<0.001$ for all outcomes ( $P$-values $<0.10$ are considered significant).

${ }^{6} \mathrm{SMD}=$ standardized mean difference.

same measurement or calculation procedures. Although there are no consensus guidelines about reporting results in these situations (Takeshima et al., 2014), we decided to report both MD and SMD. Consistent with MD results for ADG (live and carcass adjusted) and DMI, the resulting significant $\mathrm{SMD}>0.50$ indicate a moderate increase associated with LP in comparison with MS (Table 5).

\section{Effects on Health-Related Parameters}

Results from the meta-analysis models for healthrelated parameters (i.e., respiratory mortality, digestive mortality, overall mortality, and total mortality and removals) demonstrated no statistically significant differences $(P>0.05)$ between LP- and MS-fed cattle
(Fig. 4). Measures of associations from meta-analyses are presented for reference in Table 6.

\section{Effects on Carcass Parameters}

The meta-analysis for $\mathrm{HCW}$ indicated that steers fed LP were associated with a HCW increase compared with steers fed MS (Table 5; Fig. 5). Only studies where it was explicitly reported that antimicrobials (chlortetracycline or tylosin) were concurrently administered with the main interventions (LP and MS) were included for analysis of liver abscess-related outcomes. Steers fed LP had significantly greater odds of having liver abscesses $(\mathrm{OR}=1.40, P=0.01)$ and $\mathrm{A}+$ livers $(\mathrm{OR}=1.60$, $P<0.01$ ) than steers fed MS (Table 6). Laidlomycin propionate-fed steers tended to be significantly more

Table 6. Results obtained from random-effects meta-analysis models of the effects of laidlomycin propionate compared with monensin sodium on health-related outcomes and liver abscesses

\begin{tabular}{|c|c|c|c|c|c|c|}
\hline Outcome & $\begin{array}{c}\text { Number } \\
\text { of data sets }\end{array}$ & $\mathrm{OR}^{1}$ & $\begin{array}{c}95 \% \mathrm{CI}^{2} \\
\text { Lower, upper OR }\end{array}$ & $\begin{array}{c}\mathrm{OR}=1 \\
P \text {-value }\end{array}$ & $\begin{array}{c}\text { Cochran's } Q \\
P \text {-value } \\
\end{array}$ & $I^{2}, 5 \%$ \\
\hline Respiratory mortality & 9 & 1.34 & $0.36,4.99$ & 0.67 & 0.99 & 0.0 \\
\hline Digestive mortality & 8 & 1.77 & $0.92,3.41$ & 0.09 & 0.72 & 0.0 \\
\hline Overall mortality & 9 & 1.27 & $0.82,1.96$ & 0.28 & 0.79 & 0.0 \\
\hline Total mortality and removals & 10 & 1.01 & $0.76,1.34$ & 0.96 & 0.80 & 0.0 \\
\hline Proportion of A livers & 8 & 1.29 & $0.95,1.75$ & 0.10 & $<0.01$ & 75.4 \\
\hline Proportion of A+ livers & 10 & 1.60 & $1.29,1.99$ & $<0.01$ & 0.32 & 13.3 \\
\hline Total livers with abscesses & 12 & 1.40 & $1.07,1.83$ & 0.01 & $<0.01$ & 80.3 \\
\hline Total livers with no abscesses & 9 & 0.78 & $0.61,1.02$ & 0.07 & $<0.01$ & 82.5 \\
\hline
\end{tabular}

${ }^{1} \mathrm{OR}=$ odds ratio.

${ }^{2} \mathrm{CI}=$ confidence interval.

${ }^{3}$ Test of $\mathrm{OR}=1$.

${ }^{4} P$-value for Cochran's $Q$ test ( $\chi 2$ test; $\mathrm{df}=\mathrm{k}-1$, in which $k=$ number of studies) to assess the statistical significance of between-study heterogeneity. $P$-values $<0.10$ are considered significant.

$5 I^{2}=$ variation in OR attributable to heterogeneity $\left(I^{2} 25-50 \%\right.$ represents a low degree of heterogeneity, $I^{2} 50-75 \%$ represents a moderate degree of heterogeneity, and $I^{2} \geq 75 \%$ represents high degree of heterogeneity; Higgins et al., 2003). 


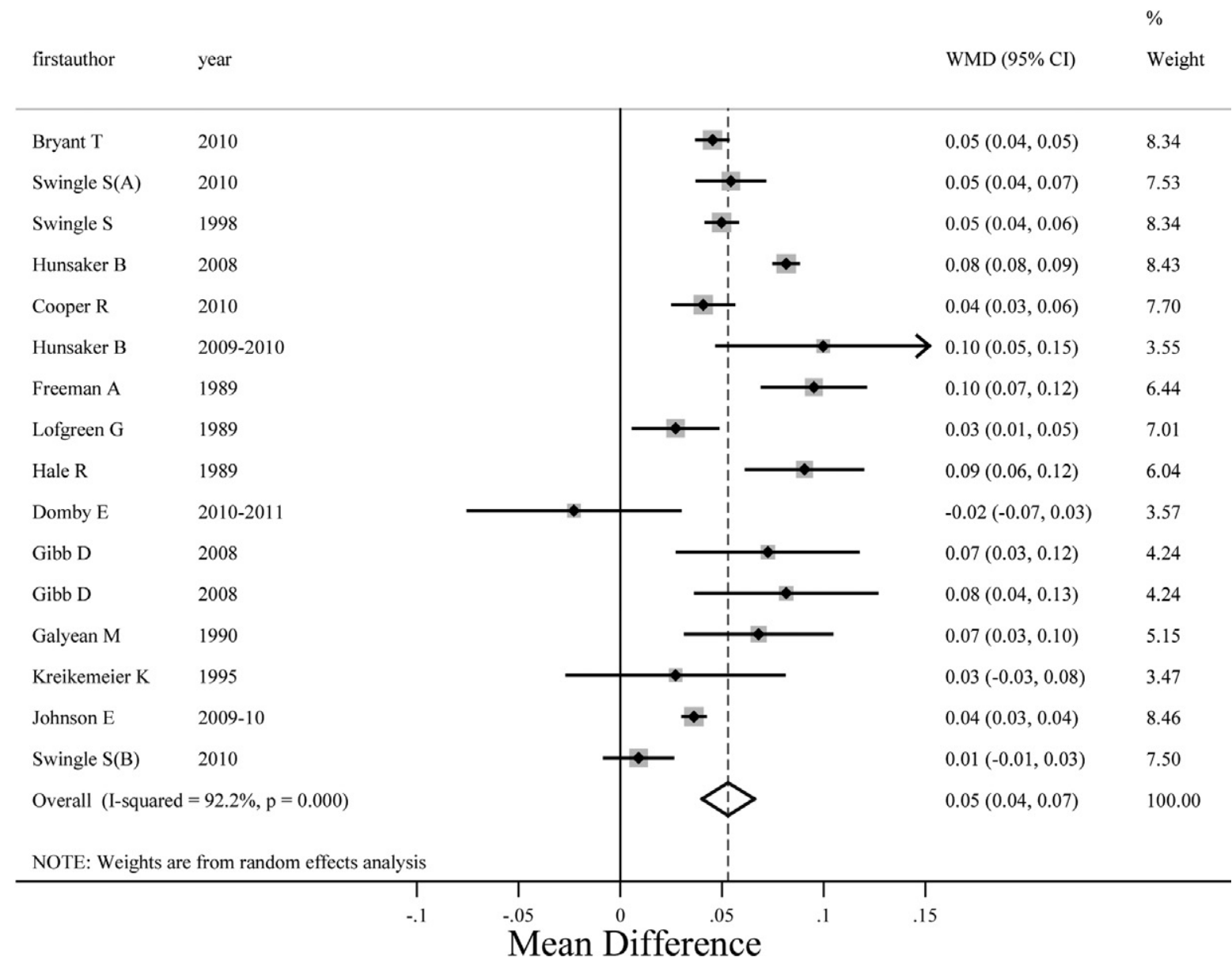

Figure 1. Forest plot obtained from random-effects meta-analysis models of the effects of laidlomycin propionate versus monensin sodium on ADG (live weight). Each horizontal line represents the results from a data set, depicted by the name of the primary investigator and the publication or study year (see Table 3). The length of the horizontal line represents the $95 \%$ confidence interval (CI) for the parameter estimate (mean difference), the center of the shaded box represents the point estimate of the parameter, and the area is proportional to the assigned weight. The empty diamond at the bottom shows the confidence interval and the dotted vertical line represents the overall effect parameter based on the random effects (DerSimonian and Laird, 1986) model. Weighted mean difference (WMD) computes a weighted average of differences in means; however, no weighting occurs when calculating a statistical summary of a single study; therefore, we refer to the results of meta-analysis as mean differences (Higgins and Green, 2011). I-squared $=\mathrm{I} 2$ or variation in MD attributable to heterogeneity (I2 $0-50 \%=1$ low heterogeneity; 50-75\% = moderate; $>75 \%$ = high heterogeneity (Higgins et al., 2003); $\mathrm{p}=P$-value for Cochran's Q test Freeman A., 1989 (Freeman et al., 1991 ); Domby E., 2010-2011 (Domby et al., 2013); Gibb D., 2008 (Gibb et al., 2008); Galyean M., 1992 (Galyean et al., 1992); Kreikemeier K., 1995 (Kreikemeier, 1997$).$

likely to have A livers $(\mathrm{OR}=1.29, P=0.10)$ but less likely to have no liver abscesses compared with MS-fed steers $(\mathrm{OR}=0.78, P=0.07$; Table 6$)$.

\section{Stratified Meta-Analyses and Meta-Regression Models}

Performance (ADG, DMI, and FE) and carcass ( $\mathrm{HCW}$, total livers with abscesses, and $\mathrm{A}$ and $\mathrm{A}+$ livers) outcomes had a substantial variability $\left(I^{2}>50 \%\right)$ in the effects of LP compared with MS between studies. A priori, it was considered that the size of study pens was a potential confounder and cause of heterogeneity among relevant studies. When stratified meta-analyses were conducted by size of study pens, this variable seemed to account for some of the heterogeneity among studies for ADG (live weight), FE (carcass adjusted), and $\mathrm{HCW}$, as indicated by numerical differences in MD and SMD for LP compared with MS in different size pens (data not shown). Overall, when stratified by size of the study pens, overall tests of between-group heterogeneity could not be interpreted, given considerable heterogeneity in 1 subgroup (pens with $>50$ steers/pen).

To explain potential causes of between-study heterogeneity, mixed-effects meta-regression models were fitted. Six to 17 studies were used to fit meta-regression models depending on outcome and explanatory variables. Given the limited number of relevant studies, only univariable models were built. The type of production setting tended to be significant $(P=0.09)$ and it explained $29 \%$ of the between-study variance for ADG based on live weight. Pen size was significant $(P=0.04)$ and it explained $59 \%$ of the between-study variance for FE (carcass adjusted). Except for these associations, there was no evidence of these explanatory variables significantly $(P>0.10)$ explaining the heterogeneity between studies for the other outcomes of interest when comparing steers fed LP and MS. 


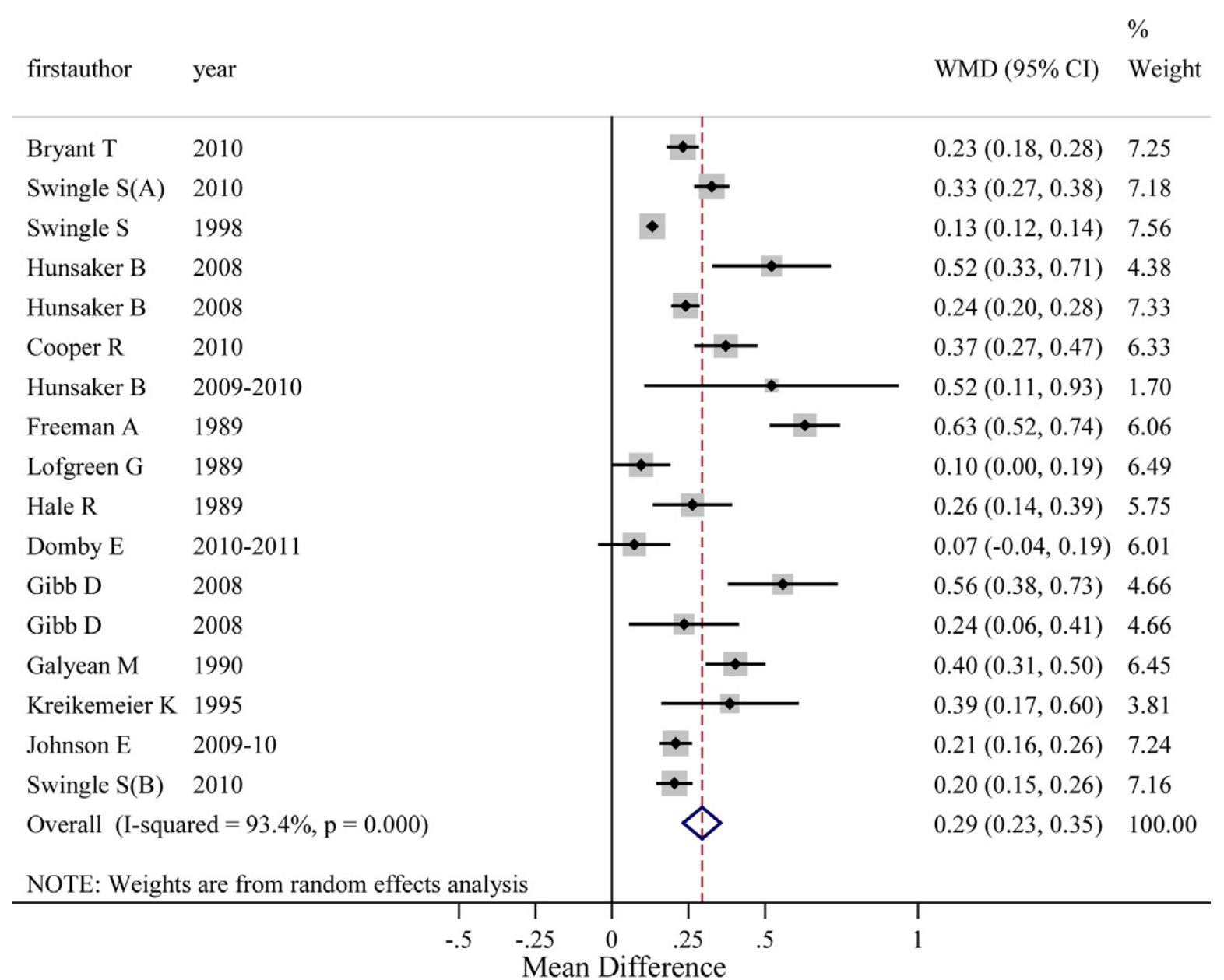

Figure 2. Forest plots obtained from random-effects meta-analysis models of the effects of laidlomycin propionate versus monensin sodium on DMI $\mathrm{WMD}=$ weighted mean difference; $\mathrm{CI}=$ confidence interval; I-squared $=\mathrm{I} 2$ or variation in $\mathrm{MD}$ attributable to heterogeneity (I2 $0-50 \%=$ low heterogeneity; $50-75 \%=$ moderate; $>75 \%=$ high heterogeneity (Higgins et al., 2003); $\mathrm{p}=P$-value for Cochran's Q test.

\section{DISCUSSION}

The meta-analysis of data from these comparative effectiveness studies demonstrate significant MD between steers fed LP and steers fed MS with respect to several important feedlot performance and carcass outcomes. Laidlomycin propionate is an ionophore approved for use in combination with chlortetracycline for improved FE and increased rate of weight gain in cattle fed in confinement for slaughter (FDA, 2015a). Monensin sodium, also an ionophore, is approved for use in combination with tylosin for increased FE in feedlot cattle and with an additional claim for the prevention and control of coccidiosis (FDA, 2015b). The results of the present study indicate beneficial effects of feeding LP as compared with MS for most feedlot performance (e.g., live and carcass-adjusted ADG) and carcass parameters (e.g., HCW) but not for others (Tables 5 and 6). Although digestive mortality tended to favor MS, none of the mortality-related outcome variables differed significantly (Table 6). Liver abscesses were significantly more common in LP-fed cattle than in MS-fed cattle (Table 6), presumably because of differences in the concurrently fed antimicrobials. Some MD may not have been identified in single field studies, as the magnitude of effects was relatively small compared with the sample sizes for individual studies and meta-analysis of results from several individual studies can increase the power for detecting effects (Dohoo et al., 2009). However, there was evidence for significant heterogeneity among studies, which could not be fully explained with the few potential explanatory variables and the relatively small number of data sets available for analyses. The significant heterogeneity among studies could be expected given the diversity of studies included. However, these results provide unique and comprehensive information on the comparative effects of different ionophores across multiple studies and in multiple years, states, and production settings.

A systematic review of multiple RCT is considered the strongest evidence for intervention efficacy in human and animal health research (Sargeant et al., 2014b). The results presented here are based on RCT that directly compared interventions (LP and MS) in a 


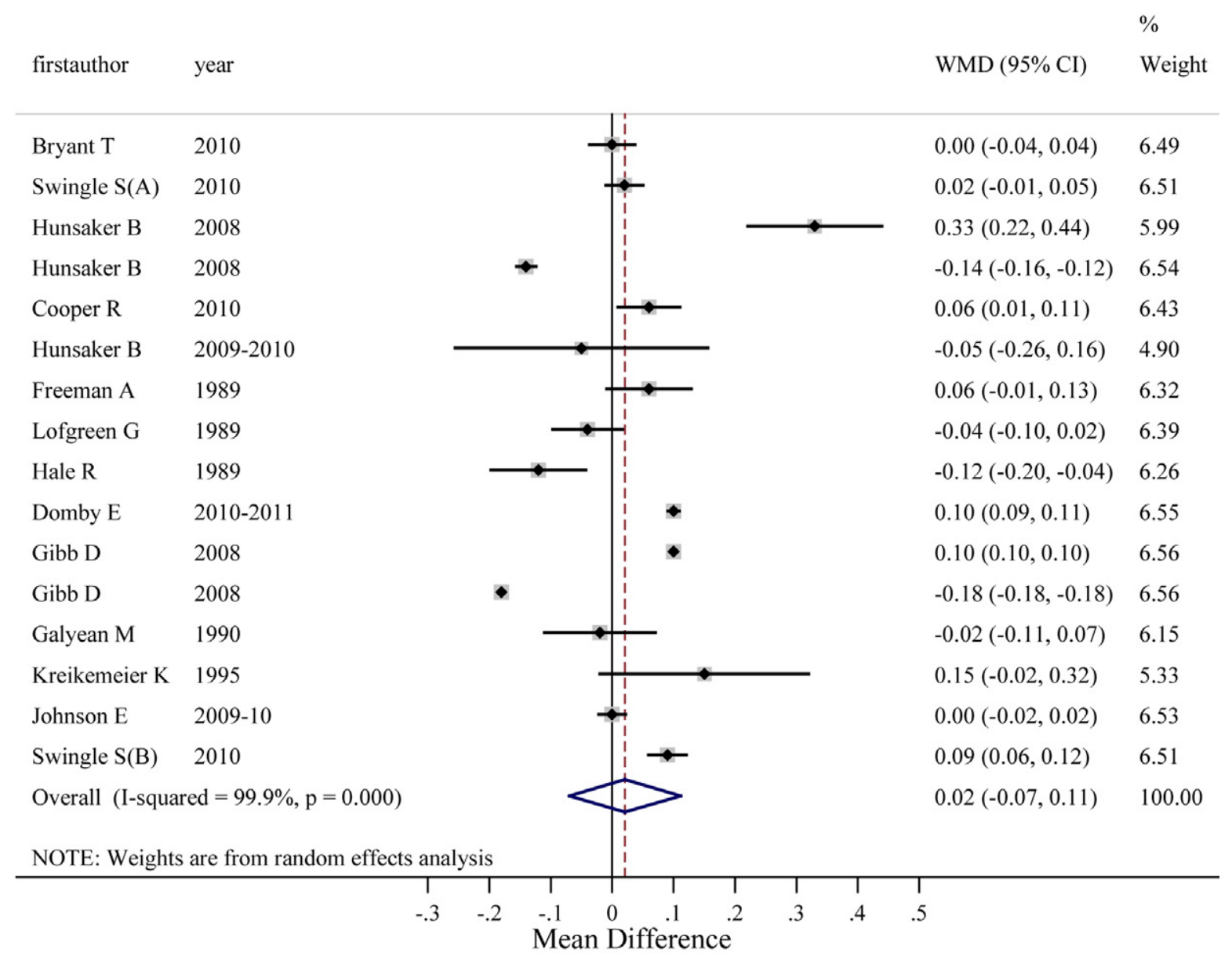

Figure 3. Forest plots obtained from random-effects meta-analysis models of the effects of laidlomycin propionate versus monensin sodium on feed efficiency (live weight; the ratio of feed weight to $\mathrm{BW}$ gain). $\mathrm{WMD}=$ weighted mean difference; $\mathrm{CI}=$ confidence interval; I-squared $=\mathrm{I} 2$ or variation in MD attributable to heterogeneity (I2 $0-50 \%=$ low heterogeneity; $50-75 \%=$ moderate; $>75 \%=$ high heterogeneity (Higgins et al., 2003 ); $\mathrm{p}=P$-value for Cochran's Q test.

comparative effectiveness format but did not include efficacy studies where interventions were compared with a negative control (for indirect comparisons of interventions). By comparing with another intervention (i.e., a positive control), the results enable interpretation of whether an intervention is "as good as" or "better than" another intervention or interventions (Sargeant et al., 2014a). Analytical approaches incorporating both direct and indirect comparisons of interventions exist and are particularly useful when treatments have not been directly compared in randomized trials (Jansen et al., 2011). Indirect comparisons, besides being statistically less precise than direct comparisons and more unpredictable, are also prone to many of the same biases as direct comparisons (Song et al., 2008). Bucher et al. (1997) and Glenny et al. (2005) have recommended that results from RCT on direct comparisons are used rather than conflicting evidence from indirect comparisons. The focus here toward including only direct comparisons aimed to increase the usefulness as well as practicability and understanding of results for the end users (O’Connor et al., 2014b).
Most studies of direct comparisons between LP and MS were not publicly available. Given the relatively common use of these interventions and the similarities in approved label indications, there was a general lack of evidence as it relates to direct comparisons between LP and MS. The limited number of direct comparisons raises the possibility for publication bias if studies with unfavorable results have not been published. Publication bias is a concern in any review that combines data from multiple sources. Because smaller studies (with larger SE) are less likely to find positive results, they may be more prone to not being published (O'Connor et al., 2014b). To avoid this potential bias, data not available to the public domain (e.g., industry reports) as well as unindexed reports (e.g., conference proceedings) were also included in this meta-analysis. In addition to articles indexed in electronic databases, a hand search of references in review papers as well as communication with scientists, manufacturing companies, and industry partners, who have been working in the relevant field, are all considered important methods for a comprehensive search (Lean et al., 2009). It may 


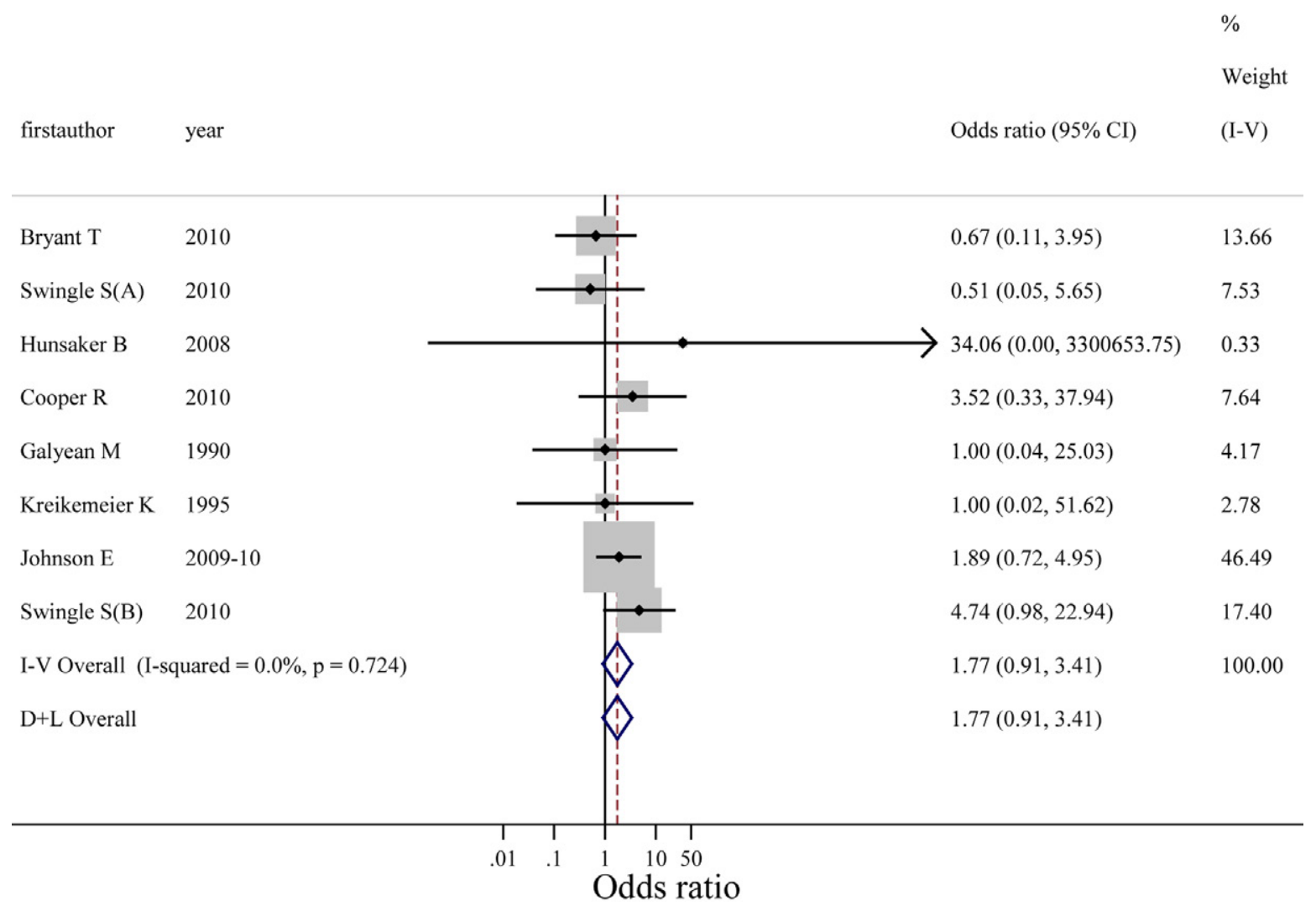

Figure 4. Forest plots obtained from fixed and random-effects meta-analysis models of the effects of laidlomycin propionate versus monensin sodium on digestive mortality. Each horizontal line represents the results from a data set, depicted by the name of the primary investigator and the publication or study year (see Table 4). The length of the horizontal line represents the $95 \%$ confidence interval (CI) for the parameter estimate (odds ratio), the center of the shaded box represents the point estimate of the parameter, and the area is proportional to the assigned weight. The empty diamonds at the bottom show the confidence intervals and the vertical dotted line represents the overall effect parameters based on fixed effects (I-V; Inverse variance) and random effects (DerSimonian and Laird, 1986) [D+L]) models. I-squared $=\mathrm{I} 2$ or variation in MD attributable to heterogeneity (I2 $0-50 \%=$ low heterogeneity; $50-75 \%=$ moderate; $>75 \%=$ high heterogeneity $($ Higgins et al., 2003); $\mathrm{p}=P$-value for Cochran's $\mathrm{Q}$ test.

not be possible to find every relevant study on a topic, but pursuing multiple avenues to find as many relevant studies as possible can minimize publication bias and increase the precision of the pooled estimates of effect while providing meaningful results of most importance to decision makers (Lean et al., 2009).

Sources of bias also can arise from lack of randomization or inadequate blinding. In the current study, randomization was implemented in all studies. Blinding was reported in only 1 of the studies; however, most outcome variables were objectively measured, and it is possible that blinding, a relatively common reporting flaw, was done but was not reported (Sargeant et al., 2014b). Given the scarcity of studies, we did not exclude any reports or publications based on the lack of reporting of blinding to treatment groups, other reporting omissions, or potential design flaws. However, studies had to be RCT and certain validity criteria had to be met (i.e., risk of assessment bias); only direct evidence from low-risk-of-bias studies was used.

Random-effects meta-analysis summary estimates were provided as they incorporate within-study and between-study variation. The summary effect mea- sures were calculated as a weighted average of the effect sizes estimated in the individual studies based on the assumption that larger studies are likely more accurate and, therefore, given larger weights (O'Connor et al., 2014b). A random-effects meta-analysis assumes that the effects being estimated in the different studies are not identical but likely follow a normal distribution. Random-effect estimates and their confidence intervals determine the average intervention effect. Furthermore, these models assume that a distribution of true treatment effects exists across studies and that included studies are a random sample of the entire population of studies, and hence, inferences can be generalized beyond the studies included (Dohoo et al., 2009).

The summary estimates from these models should be interpreted with caution given the substantial between-study heterogeneity identified. When pen size and type of production setting were analyzed as potential causes of heterogeneity, they only partially explained the between-study variability for a few of the modeled outcomes. Unfortunately, data on other potentially explanatory variables (e.g., diet) were not consistently reported for the included studies and, consequently, could 


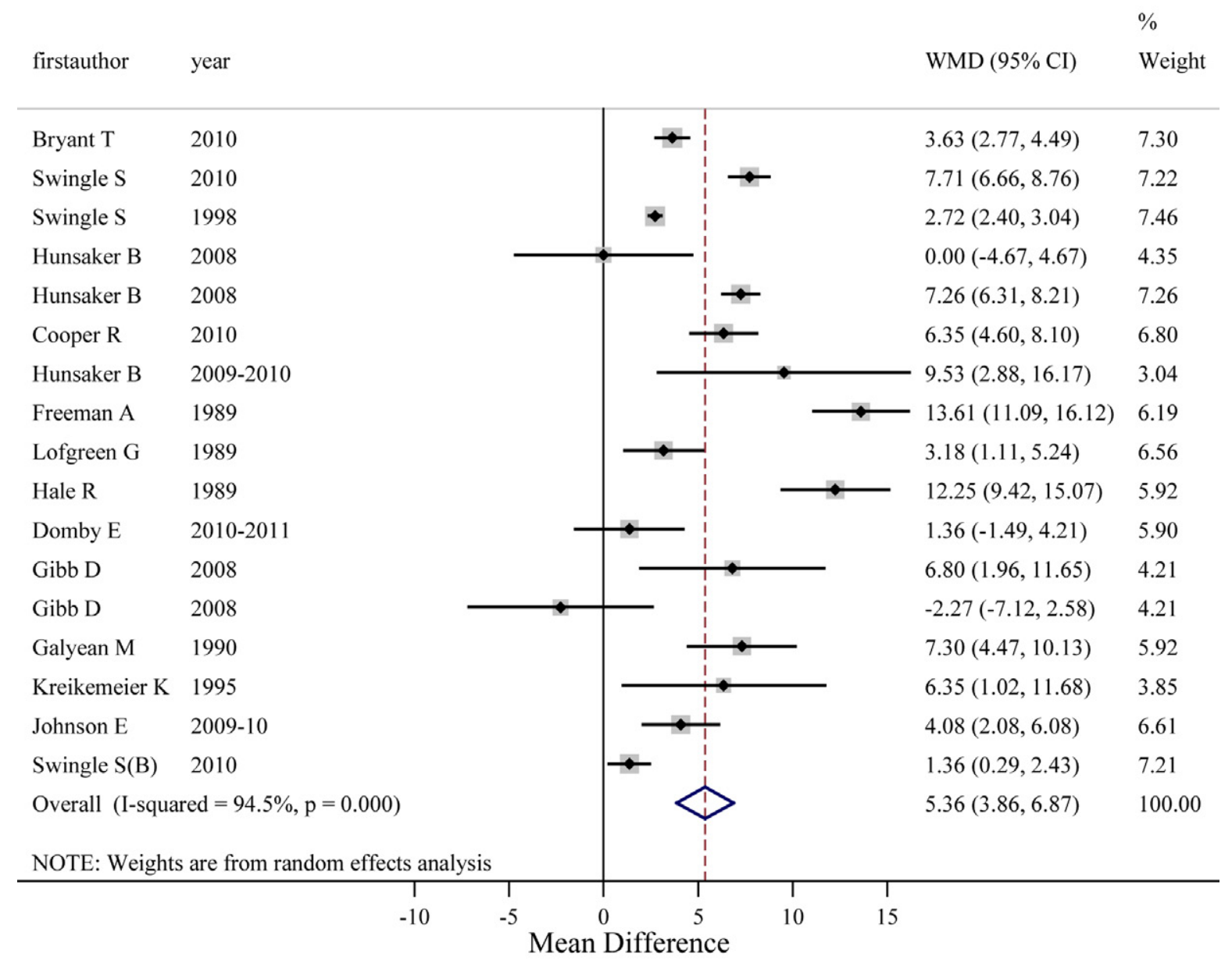

Figure 5. Forest plots obtained from fixed and random-effects meta-analysis models of the effects of laidlomycin propionate versus monensin sodium on digestive mortality. Each horizontal line represents the results from a data set, depicted by the name of the primary investigator and the publication or study year (see Table 3). The length of the horizontal line represents the $95 \%$ confidence interval (CI) for the parameter estimate (odds ratio), the center of the shaded box represents the point estimate of the parameter, and the area is proportional to the assigned weight. The empty diamonds at the bottom show the confidence intervals and the vertical dotted line represents the overall effect parameters based on fixed effects (I-V; Inverse variance) and random effects (DerSimonian and Laird, 1986) models.

not be assessed. Caution should also be exercised when interpreting the results of the stratified meta-analyses and meta-regression models, as the number of studies included in each group was small. Higgins and Green (2011) proposed that a minimum of 10 studies are necessary for conducting meta-regression analyses. As indicated by O'Connor et al. (2014b), there is no consensus as to which pathway to take when unexplained heterogeneity is present. Therefore, we chose to report all relevant results and their potential limitations. The heterogeneity among studies was not unexpected given the diversity of studies with regard to year and site, and likely differences in cattle such as genetics, and management factors including advances in growth technologies and feed rations - a factor that is known to affect the performance responses of feedlot cattle fed ionophores (Vogel, 1995; Duffield et al., 2012).

The efficacy of ionophores for improving cattle performance has been well documented in numerous studies (reviewed in Vogel, 1995; Birkelo, 2003). Recently,
Duffield et al. (2012) conducted a meta-analysis of the effects of monensin (compared with negative controls) on performance parameters in beef cattle. However, this current report is the first systematic review and metaanalysis to directly compare different ionophores (and their concurrently fed antimicrobials) and evaluate their comparative effectiveness on performance, carcass, and health-related outcomes in a feedlot setting. Across a diverse group of studies, there was an average increase in feed intake, weight gain, and HCW in steers fed LP compared with those fed MS (Table 5); the linkages among these 3 outcomes are relatively intuitive. When addressing liver abscess data, studies not reporting the concurrent use of antimicrobials (chlortetracycline and tylosin) were not included in the meta-analyses, as these drugs are fed in combination with the interventions of interest for the purpose of disease prevention. The significant MD among treatments with regard to liver abscess data were not unexpected, given that tylosin has long been considered the most effective antimicrobial for preventing liver 
abscesses (Nagaraja and Chengappa, 1998). In fact, it is important to explicitly state that the effects of ionophores and the effects of the concurrently fed antimicrobials cannot be separated in this study. Most studies $(71 \%, 12 / 17)$ used feeding programs consisting of an ionophore and an antimicrobial; hence, we could not disentangle specific effects that can be attributed to each product. However, this is a necessary and practical approach in studying their field effectiveness given the labeled usages of these products and their most common usages in the industry. It is also important to mention that all analyses and effect measures are for relative difference (i.e., relative differences between LP and MS), not measures of efficacy as compared with a negative control.

In conclusion, there were 17 data sets from over 20 $\mathrm{yr}$ of research trials that could be used to assess the comparative effectiveness of feeding LP and MS in feedlot steers, but there was significant heterogeneity among studies that could not be fully explained in meta-regression models. Nevertheless, the data indicated significant relative improvements in live and carcass performance for LP-fed steers compared with MS-fed steers but negative relative effects on liver abscesses. These unique results can enable quantitative and informed decisions by potential end users of these feed additives that are widely used in the U.S. beef industry for reducing the costs of beef production through increased cattle performance (Birkelo, 2003; USDA, 2011).

\section{LITERATURE CITED}

Birkelo, C. P. 2003. Pharmaceuticals, direct-fed microbials, and enzymes for enhancing growth and feed efficiency of beef. Vet. Clin. North Am. Food Anim. Pract. 19:599-624. doi:10.1016/S0749-0720(03)00059-8.

Bradburn, M. J., J. J. Deeks, and D. G. Altman. 1998. Metan-A command for meta-analysis in Stata. Stata Tech. Bull. 44. Stata Press, StataCorp LP, College Station, TX. p. 4-15.

Bucher, H. C., G. H. Guyatt, L. E. Griffith, and S. D. Walter. 1997. The results of direct and indirect treatment comparisons in meta-analysis of randomized controlled trials. J. Clin. Epidemiol. 50:683-691. doi:10.1016/S0895-4356(97)00049-8.

Callaway, T. R., T. S. Edrington, J. L. Rychlik, K. J. Genovese, T. L. Poole, Y. S. Jung, K. M. Bischoff, R. C. Anderson, and D. J. Nisbet. 2003. Ionophores: Their use as ruminant growth promotants and impact on food safety. Curr. Issues Intest. Microbiol. 4:43-51.

Cohen, J. 1988. Statistical power analysis in the behavioral sciences. 2nd edition. Lawrence Erlbaum Associates, Inc., Hillsdale, NJ.

DerSimonian, R., and N. Laird. 1986. Meta-analysis in clinical trials. Control. Clin. Trials 7:177-188. doi:10.1016/01972456(86)90046-2.

Dohoo, I., W. Martin, and H. Stryhn. 2009. Systematic reviews and meta-analysis. In: Veterinary epidemiologic research. 2nd ed. VER Inc., Charlottetown, PEI, Canada. p. 739-771.
Domby, E. M., J. S. Schutz, J. J. Wagner, T. E. Engle, K. L. Neuhold, D. R. Woerner, and M. E. Branine. 2013. The effect of medicinal feed additive programs and dietary sulfur concentrations in steam-flaked corn diets containing wet distillers grains on performance and carcass merit in yearling feedlot steers. Prof. Anim. Sci. 29:566-574.

Donner, A., G. Piaggio, and J. Villar. 2001. Statistical methods for the meta-analysis of cluster randomization trials. Stat. Methods Med. Res. 10:325-338.

Duffield, T. F., J. K. Merrill, and R. N. Bagg. 2012. Meta-analysis of the effects of monensin in beef cattle on feed efficiency, body weight and dry matter intake. J. Anim. Sci. 90:45834592. doi:10.2527/jas.2011-5018.

Freeman, A. S., H. R. Spires, and R. L. Botts. 1991. Performance of feedlot steers fed high energy diets containing laidlomycin propionate with and without antibiotics. Cattle Feeders' Day. Report of Progress 632. Kansas State University, Agricultural Experiment Station and Cooperative Extension Service. Southwest ResearchExtension Center. http://www.k-state.edu/historicpublications/ pubs/SRP632.pdf. (Accessed 27 August 2015.) p. 2-6.

Galyean, M. L., K. J. Malcolm, and G. C. Duff. 1992. Performance of feedlot steers fed diets containing laidlomycin propionate or monensin plus tylosin, and effects of laidlomycin propionate concentration on intake patterns and ruminal fermentation in beef steers during adaptation to a high-concentrate diet. J. Anim. Sci. 70:2950-2958.

Gibb, D. J., M. Streeter, K. S. Schwartzkopf-Gensweing, and T. A. McAllister. 2008. Performance and bunk attendance of cattle fed steam-rolled or ground corn supplemented with laidlomycin and chrlortetracycline or monensin and tylosin. Can. J. Anim. Sci. 88:499-506. doi:10.4141/CJAS07069

Glenny, A. M., D. G. Altman, F. Song, C. Sakarovitch, J. J. Deeks, R. D'Amico, M. Bradburn, and A. J. Eastwood. 2005. Indirect comparisons of competing interventions. Health Technol. Assess. 9:1-134. doi:10.3310/hta9260.

Higgins, J. P., and S. Green, editors. 2011. Cochrane handbook for systematic reviews of interventions. Version 5.1.0. The Cochrane Collaboration. http://www.cochrane-handbook.org. (Accessed 26 June 2015.)

Higgins, J. P., and S. G. Thompson. 2004. Controlling the risk of spurious findings from meta-regression. Stat. Med. 23:16631682. doi:10.1002/sim. 1752.

Higgins, J. P., S. G. Thompson, J. J. Deeks, and D. G. Altman. 2003. Measuring inconsistency in meta-analyses. BMJ 327:557-560. doi:10.1136/bmj.327.7414.557.

Jansen, J. P., R. Fleurence, B. Devine, R. Itzler, A. Barrett, N. Hawkins, K. Lee, C. Boersma, L. Annemans, and J. C. Cappelleri. 2011. Interpreting indirect treatment comparisons and network meta-analysis for health-care decision making: Report of the ISPOR task force on indirect treatment comparisons good research practices: Part 1. Value Health 14:417428. doi:10.1016/j.jval.2011.04.002.

Kreikemeier, K. K. 1997. Comparison of laidlomycin propionate and monensin at equal feed intakes. Cattle Feeders' Day. Report of Progress 794. Kansas State University, Agricultural Experiment Station and Cooperative Extension Service. Southwest Research-Extension Center. http://www.asi.kstate.edu/species/beef/research-and-extension/1997CFD.pdf (Accessed 23 March 2015.) p. 7-11.

Lean, I. J., A. R. Rabiee, T. F. Duffield, and I. R. Dohoo. 2009. Invited review: Use of meta-analysis in animal health and reproduction: Methods and applications. J. Dairy Sci. 92:35453565. doi:10.3168/jds.2009-2140. 
Mederos, A., L. Waddell, J. Sanchez, D. Kelton, A. S. Peregrine, P. Menzies, J. VanLeeuwen, and A. Rajic. 2012. A systematic review-meta-analysis of primary research investigating the effect of selected alternative treatments on gastrointestinal nematodes in sheep under filed conditions. Prev. Vet. Med. 104:1-14. doi:10.1016/j.prevetmed.2011.10.012.

Nagaraja, T. G., and M. M. Chengappa. 1998. Liver abscesses in feedlot cattle: A review. J. Anim. Sci. 23:351-369.

O'Connor, A. M., K. M. Anderson, C. K. Goodell, and J. M. Sargeant. 2014a. Conducting systematic reviews of intervention questions I: Writing the review protocol, formulating the question and searching the literature. Zoonoses Public Health 61:28-38. doi:10.1111/zph.12125.

O'Connor, A. M., J. M. Sargeant, and C. Wang. 2014b. Conducting systematic reviews of intervention questions III: Synthetizing data from intervention studies using meta-analysis. Zoonoses Public Health 61:52-63. doi:10.1111/zph.12123.

Russell, J. B., and H. J. Strobel. 1989. Effect of ionophores on ruminal fermentation. Appl. Environ. Microbiol. 55:1-6.

Sargeant, J. M., D. F. Kelton, and A. M. O'Connor. 2014a. Randomized controlled trials and challenge trials: Design and criterion for validity. Zoonoses Public Health 61:18-27. doi:10.1111/zph.12126.

Sargeant, J. M., D. F. Kelton, and A. M. O’Connor. 2014b. Study designs and systematic reviews of interventions: Building evidence across study designs. Zoonoses Public Health 61:10 17. doi:10.1111/zph.12127.
Song, F., I. Harvey, and R. Lilford. 2008. Adjusted indirect comparison may be less biased than direct comparison for evaluating new pharmaceutical interventions. J. Clin. Epidemiol. 61:455-463. doi:10.1016/j.jclinepi.2007.06.006.

Takeshima, N., T. Sozu, A. Tajika, Y. Ogawa, Y. Hayasaka, and T. A. Furukawa. 2014. Which is more generalizable, powerful and interpretable in meta-analyses, mean difference or standardized mean difference? BMC Med. Res. Methodol. 14:30. doi:10.1186/1471-2288-14-30.

USDA. Feedlot 2011. Part III: Trends in health and management practices on U.S. feedlots, 1994-2011. https://www.aphis.usda. gov/animal_health/nahms/feedlot/downloads/feedlot2011/ Feed11_dr_Part\%20III.pdf. (Accessed 26 June 2015.)

U.S. Food and Drug Administration (FDA). 2015a. Animal and veterinary drug products. NADA 141-025 Cattlyst $\AA$ - original approval. http://www.fda.gov/AnimalVeterinary/Products/ ApprovedAnimalDrugProducts/FOIADrugSummaries/ ucm132769.htm (Accessed 26 June 2015.)

U.S. Food and Drug Administration (FDA) 2015b. NADA 095-735 Rumensin - supplemental approval (October 22, 1990). http://www.fda.gov/AnimalVeterinary/Products/ ApprovedAnimalDrugProducts/FOIADrugSummaries/ ucm064811.htm. (Accessed 26 June 2015).

Vogel, G. 1995. The effect of ionophores on feed intake by feedlot cattle. Lilly Research Laboratories, Canyon, TX. 